\title{
1 Supercritical sage extracts as anti-inflammatory food ingredients
}

2 E. Arranz ${ }^{\mathrm{a}}$, L. Jaime ${ }^{\mathrm{a}}$, M. C. Lopez de la Hazas ${ }^{\mathrm{a}}$, G. Vicente ${ }^{\mathrm{a}}$, G. Reglero ${ }^{\mathrm{a}, \mathrm{b}}$, S.

3 Santoyo $^{\mathrm{a}, *}$

$4{ }^{\text {a }}$ Instituto de Investigación en Ciencias de la Alimentación (CIAL). Universidad 5 Autónoma de Madrid. 28049 Madrid, Spain

6 b Imdea-Food Institute, Universidad Autónoma de Madrid, 28049 Madrid, Spain 7

8 Key words: Sage, anti-inflammatory activity, supercritical extracts, anti-inflammatory 9 cytokines, anti-atherogenic model.

11 Running title: anti-inflammatory activity of sage

$13 *$ Corresponding author:

14 Susana Santoyo

15 Instituto de Investigación en Ciencias de la Alimentación (CIAL)

16 Campus de la Universidad Autónoma de Madrid

17 c) Nicolás Cabrera 9

$18 \quad 28049$, Madrid

19 Spain 
Tef: 34910017926

21

e-mail: susana.santoyo@uam.es

22

23 Abstract

24 The anti-inflammatory capacity of supercritical $\mathrm{CO}_{2}$ extracts ( $\mathrm{S} 1$ and $\mathrm{S} 2$ ) obtained from sage (Salvia officinalis) was evaluated using THP-1 human macrophages activated with human ox-LDL, a specific in vitro model to determine the anti-inflammatory effect of the extracts in an atherosclerotic environment. The expression of pro-inflammatory cytokines, with an important role in the atherogenic process, such as TNF- $\alpha$, IL-1 $1 \beta$ and IL-6, in presence of different extracts concentrations was evaluated. Results showed that $30 \mu \mathrm{g} / \mathrm{mL}$ of both supercritical extracts (S1 and S2) markedly suppressed the ox-LDL induced production of TNF- $\alpha$, IL- $1 \beta$ and IL-6, as well as their mRNA expression. Data showed that S1 presented a higher anti-inflammatory activity than S2.

A characterization by GC-MS of sage extracts identified 16 compounds, mainly camphor, borneol and 1,8-cineole. These three compounds represented a $62.4 \%$ of S1 and a $48.1 \%$ of S2. Camphor, borneol and 1,8-cineole presented an important antiinflammatory activity in the proposed model, with a decrease in the release and gene expression of TNF- $\alpha$, IL- $1 \beta$ and IL- 6 and an increase in IL-10 expression. These results explained the higher activity found in $\mathrm{S} 1$.

This study suggested that supercritical sage extracts could be used as food ingredients in the development of anti-inflammatory/anti-atherogenic products. 


\section{Introduction}

Atherosclerosis consists of cholesterol deposition in the intima of large and medium size arteries, accompanied by a chronic inflammatory process (Barter, 2005). A large body of evidence supports the key role of oxidized low-density lipoproteins (ox-LDL) in the early inflammatory and more advances stages of the atherosclerosis lesions. OxLDL are not recognized by the LDL receptor apo (B/E), but taken up in a non-regulated manner by the scavenger receptors in monocytes-macrophages and endothelial cells. This process leads to the accumulation of cholesterol in the macrophages, forming foam cells, the hallmark of the atherosclerosis lesion (Chouinard et al., 2008). In addition, these ox-LDLs can induce the expression of adhesion molecules, pro-inflammatory cytokines (such as TNF- $\alpha$, Il-1 $\beta$, and IL-6) and other mediators of inflammation in macrophages and endothelial cells (Kaperonis et al., 2006).

The functional role of herbs and spices and their constituents is a hot topic in food related plant research. Herbs and spices, that have been added to foods since ancient times, mainly to modify or improve their flavor, are nowadays also appreciated for their biological activities. Extracts and essential oils obtained from several herbs and spices present different biological activities, including antioxidant, anti-inflammatory, antitumoral, antiviral and antimicrobial activities (Hamdy et al., 2013; Chan et al., 2011; Tajkarimi et al., 2010; Kaefer and Milmer, 2008; Santoyo et al., 2006a; Santoyo et al., 2006b; Shin and Kim, 2002). The genus Salvia is, with about 900 species, one of the most widespread members of the Lamiaceae family. Although sage is a popular kitchen herb, it has one of the longest histories of use as medicinal herb. The positive benefits of Salvia officinalis (common sage) to health are reputed throughout Ancient Romans times to the Middle Ages; thus this herb has been commonly used for treating 
colds, coughs and bronchial infections. Some studies have reported that species of the genus Salvia possess specific characteristics which could be used as anti-inflammatory agents. The in vitro anti-inflammatory activity of several essential oils and solvent extracts of Salvia species was evaluated using the 5-lipoxygenase assay, indicating that, in general, essential oils exhibited better anti-inflammatory activity than solvents extracts (Kamatou et al., 2005). Kamatou et al. (2008) reported the anti-inflammatory activity of the essential oils of Salvia rapens, Salvia runcinata and Salvia stenophylla measuring the inhibition of cyclo-oxigenase-1 (COX-1) and COX-2, two key enzymes in the inflammation process. The results indicated that the three essential oils inhibited COX-2 enzyme, being Salvia stenophylla the most active. Also Mueller et al., (2010) indicated that an extract from Salvia officinalis presented anti-inflammatory activity, since this extracts moderately reduced the secretion of pro-inflammatory cytokines like IL-6 and TNF- $\alpha$. In the same way, Wang et al. (2006), reported that an extract from Salvia miltiorrhiza was able to suppress LPS-induced TNF- $\alpha$ in human peripheral blood leukocytes and RAW 264.7 macrophage cell line. Using the same inflammation model, more recently Abu-Darwish et al. (2013) described a reduction in NO production after the incubation of activated cells with common sage extracts obtained by hydrodistillation. Besides, Ehrnhöfer-Ressler et al. (2013) indicated the antiinflammatory activity of a S. officinalis infusion was due to a reduction of IL-6 and IL-8 release in activated human gingival fibroblasts. Using an in vivo model of inflammation, carrageenan-induced edema in rats, different extracts obtained from Salvia species showed anti-inflammatory and anti-edematous activity (Çadirci et al., 2012), specifically hydroalcoholic extracts showed anti-inflammatory activity, correlated with inhibition of inflammatory mediators release (Alves et al., 2012). 
In recent years, supercritical fluid extraction (SFE) has received increased attention as an important alternative to the traditional solvent extraction methods, since this technique provides a high speed and efficiency of extraction, eliminates concentration steps and avoids the use of organic solvents which are potentially harmful in terms of environmental impact. SFE is an extraction/fractionation method that exploits the unique properties of gases above their critical points to extract soluble components from a raw material. Carbon dioxide is an ideal solvent for the extraction of some classes of natural substances from food because is non-toxic, non-explosive, readily available and easy to remove from extracted products. In that way, the quality of supercritical fluid extracts is higher than those obtained by extraction solvents, water or steam distillation, since these methods can induce thermal degradation or present the problem of toxic residual solvent in the products (Diaz-Maroto et al., 2002). In particular, SFE has been applied to obtain extracts and fractions from S. officinalis essential oils with a higher terpenoids content than when employing traditional techniques (Aleksovski and Sovová 2007; Gañán and Brignole, 2013; Maksimovic et al., 2013). Thus, the combination of SFE and other extraction methods, such as ultrasound-assisted extraction, have been also used to concentrated sage extracts in diterpenes, the main valuable components (Glisic et al., 2011).

The aim of this paper was to study the anti-inflammatory capacity of Salvia officinalis supercritical extracts using THP-1 human macrophages activated with human ox-LDL. This model of inflammation allowed us to determine the anti-inflammatory effect of the extracts in an atherosclerotic environment and could be useful to determine the potential activity of the extracts in the prevention of atherosclerosis. Also, this model has been used only in few studies, since most of anti-inflammatory studies reported used 
114 lipopolysaccharide to activate macrophages. Further, this work analysed the chemical 115 composition of the extracts and intended to establish a relationship between the 116 extracts' activity and their composition.

\section{Material and methods}

\subsection{Samples and chemicals}

Sage (Salvia officinalis) sample consisted of dried leaves obtained from a herbalist's shop (Murcia, Spain). Cryogenic grinding of the samples was performed under liquid nitrogen. The size of the particle was determined by passing the ground plant material through sieves between 1000-500 $\mu \mathrm{m}$ (CISA, Barcelona, Spain). The whole sample was stored at $-20^{\circ} \mathrm{C}$ until use.

1,8-cineole, camphor and borneol standards were purchased from Sigma (Madrid, Spain). $\mathrm{CO}_{2}$ (N38 quality) was supplied from Air Liquid (Madrid, Spain).

\subsection{Extraction methods}

129 Supercritical extractions were carried out using a pilot-plant supercritical fluid extractor 130 (Thar Technology, Pittsburgh, PA, USA, model SF2000), comprising a 2 L cylinder extraction cell and two different separators (S1 and S2), each of $0.5 \mathrm{~L}$ capacity, with independent control of temperature and pressure. For each experiment, the extraction vessel was packed with $0.6 \mathrm{~kg}$ of the cryogenically milled and sieved plant particles.

134 Extraction assays were performed at $30 \mathrm{MPa}$ and $313 \mathrm{~K}$, with a $\mathrm{CO}_{2}$ flow rate of 50 $\mathrm{g} / \mathrm{min}$. Temperature was set to $313 \mathrm{~K}$ in both $\mathrm{S} 1$ and $\mathrm{S} 2$ separators. In the first separator 
137 pressure was ambient pressure. The cascade decompression system produced two 138 different extracts with different composition which were collected in separator 1 (S1) 139 and separator 2 (S2) respectively. According to previous kinetic studies the overall 140 extraction time was set to be $8 \mathrm{~h}$ (García-Risco et al., 2011).

141 Solid-liquid (S/L) extractions using ethanol and methanol with chloroform were carried 142 out according to the methods describe by Kamatou et al. $(2010,2005)$, with several 143 modifications. For each experiment, $2 \mathrm{~g}$ of cryogenically milled and sieved plant 144 particles were dissolved in $100 \mathrm{~mL}$ of $100 \%$ of ethanol or $100 \mathrm{~mL}$ of methanol:chloroform $(1: 1)$ to obtain two different extracts. In both cases the extraction time was $4 \mathrm{~h}$ at $310 \mathrm{~K}$ with shaking $(200 \mathrm{rpm})$ and the process was repeated 3 times.

147 The extracts were obtained by removing the solvents with a rotary evaporator at $40{ }^{\circ} \mathrm{C}$.

\subsection{GC-MS analysis}

149 Characterization of the supercritical sage extracts was carried out by a GC-2010 150 (Shimadzu, Japan), equipped with a split/splitless injector, electronic pressure control, AOC-20i auto injector, GCMS-QP2010 Plus mass spectrometer detector, and a GCMS Solution software. The column used was a ZB-5 (Zebron) capillary column, $30 \mathrm{~m}$ x 0.32 mm I.D. and $0.25 \mu \mathrm{m}$ phase thickness. Helium, $99.996 \%$ was used as a carrier gas at a

154 flow of $1 \mathrm{~mL} / \mathrm{min}$. Oven temperature programming was $60^{\circ} \mathrm{C}$ isothermal for $4 \mathrm{~min}$, 155 increased to $64{ }^{\circ} \mathrm{C}$ at $1{ }^{\circ} \mathrm{C} / \mathrm{min}$, then increased to $106{ }^{\circ} \mathrm{C}$ at $2.5{ }^{\circ} \mathrm{C} / \mathrm{min}$. Oven temperature was then increased from $106^{\circ} \mathrm{C}$ to $130{ }^{\circ} \mathrm{C}$ at $1{ }^{\circ} \mathrm{C} / \mathrm{min}$, and then to $200{ }^{\circ} \mathrm{C}$ at $5{ }^{\circ} \mathrm{C} / \mathrm{min}$, and then to a final temperature of $250{ }^{\circ} \mathrm{C} / \mathrm{min}$ at $8{ }^{\circ} \mathrm{C} / \mathrm{min}$ which was kept constant for $10 \mathrm{~min}$. Sample injections $(1 \mu \mathrm{L})$ were performed in split mode (1:20). The inlet pressure of the carrier gas was $57.5 \mathrm{KPa}$. Injector temperature was of $250{ }^{\circ} \mathrm{C}$ and MS ion source and interface temperatures were 230 and $280{ }^{\circ} \mathrm{C}$, respectively. The mass 
161 spectrometer was used in TIC mode, and samples were scanned from 40 to $500 \mathrm{amu}$.

162 Compounds 1,8-cineole, camphor, borneol and linalool were identified by comparison 163 with standard mass spectra obtained in the same conditions and compared with the mass 164 spectra from library Wiley 229. The rest of the compounds were identified by 165 comparison with the mass spectra from Wiley 229 library and by their linear retention 166 index.

LDLs were isolated from human plasma as described before (Havel et al., 1995).

Oxidation of LDLs was done by incubating LDLs with $5 \mu \mathrm{M} \mathrm{CuSO}$ for $3 \mathrm{~h}$ at $37^{\circ} \mathrm{C}$.

Oxidation degree was measured as the amount of thiobarbituric acid reactive substances (TBARS) produced.

\subsection{Cell culture and treatment}

Human THP-1 monocytes (American Type Culture Collection, ATCC) were cultured in RPMI 1640 culture medium (Gibco, Spain) supplemented with 10\% FBS, $100 \mathrm{U} / \mathrm{mL}$ penicillin, $100 \mathrm{mg} / \mathrm{mL}$ streptomycin, $2 \mathrm{mM}$ L-glutamine and $0.05 \mathrm{mM} \beta-$ mercaptoethanol at $37^{\circ} \mathrm{C}$ in $95 \%$ humidified air containing $5 \% \mathrm{CO}_{2}$. Cells were collected and plated at a density of $5 \times 10^{5}$ cells $/ \mathrm{mL}$ in 24 wells plates. Differentiation to macrophages (THP-1/M cells) was induced by maintaining the THP-1 cells in the 181 presence of $100 \mathrm{ng} / \mathrm{ml}$ phorbol 12-myristate 13-acetate (PMA) (Sigma, Spain) for 48h. 182 After differentiation, cells were washed with PBS and incubated with $75 \mu \mathrm{g} / \mathrm{mL}$ oxLDLs in presence of different concentrations of supercritical extracts, S/L extracts or pure standards for $24 \mathrm{~h}$ in a FBS free medium. Then, the supernatant was frozen at $-80^{\circ} \mathrm{C}$ 
and cells RNA isolated. Indomethacin $(4 \mu \mathrm{g} / \mathrm{mL})$, an anti-inflammatory drug, was used as a reference.

\subsection{Cytotoxicity assays}

The cytotoxic effect of the extracts and pure standards on THP-1/M cells was tested using 3-(4,5-dimethylthiazol-2-yl)-2,5-diphenyl tetrazolium bromide (MTT) assay (Sigma, Spain), according to a publish method (Mosmann, 1983). THP-1/M cells in 24multiwell plates were incubated with RPMI containing different concentrations of the extracts for $24 \mathrm{~h}$ at $37^{\circ} \mathrm{C}$. Cells were then washed with PBS and $0.5 \mathrm{mg} / \mathrm{ml}$ of MTT were added to each well and incubated $4 \mathrm{~h}$ at $37^{\circ} \mathrm{C}$. Supernatants were discarded and formazan crystals dissolved in an extraction solution (10\% sodium dodecyl sulphate in a mixture of dimethyl formamide and water $1: 1 \mathrm{v} / \mathrm{v}$, adjusted to $\mathrm{pH} 4.7$ with acetic acid) overnight at $37^{\circ} \mathrm{C}$. Formazan quantification was performed by measuring the optical density at $570 \mathrm{~nm}$ using a multiscanner autoreader (Sunrise, Tecan) with the extraction solution as a blank. The data were plotted as dose-response curves, from which the concentration required to reduce $50 \%$ the number of viable THP-1/M $\left(\mathrm{CC}_{50}\right)$ after $24 \mathrm{~h}$ of incubation with the different extracts were obtained.

\subsection{Quantification of cytokines by ELISA}

The release of IL-1 $\beta$, IL-10, IL- 6 and TNF- $\alpha$ was measured in the supernatants of THP1/M cells treated with ox-LDL in presence of different concentrations of sage extracts and standards using ELISA kits (BD biosciences, Spain), according to manufacturer's instructions. The color generated was determined by measuring the OD at $450 \mathrm{~nm}$ using a multiscanner autoreader (Sunrise, Tecan). 
211 RNA was isolated from THP-1/M cells using Trizol ${ }^{\circledR}$ (Invitrogen, Spain) according to 212 manufacturer's instructions. Reverse transcription (RT) of the RNA was performed 213 using High Capacity Archive Kit and GeneAmp PCR System 9700 (Applied 214 Biosystems, Carlsbad, CA, USA) according to the manufacturer's instructions to obtain $21520 \mathrm{ng} / \mu \mathrm{L}$ of cDNA. PCR amplification was conducted in a $10 \mu \mathrm{L}$ reaction mixture with cDNA, Taqman Gene Expression Master Mix (Applied Biosystems) and TaqMan probes (Applied Biosystems) according to the manufacturer's conditions in a 7900HT Fast Real-Time PCR System (Applied Biosystems). The TaqMan probes used were as follows: Hs99999029_m1 for IL-1ß, Hs00174131_m1 for IL-6, Hs99999035_m1 for IL-10, Hs00174128_m1 for TNF- $\alpha$ and Hs99999901_s1 for 18S rRNA. Expression of genes was normalized relative to $18 \mathrm{~S}$ rRNA using SDS Software v2.4 (Applied Biosystems).

\subsection{Statistical analysis}

225 All data were expressed as the mean of three determinations \pm SD. Data were analyzed by one-way analysis of variance (ANOVA) followed by Dunnett's and Bonferroni tests, using Prism program for Windows (Version 5; GraphPad Software, San Diego, CA, USA). P values lower than 0.05 were considered significant.

\section{Results}

Extraction of sage leaves by using supercritical carbon dioxide was carried out on a pilot scale plant. Usually, the first step was to determine both, the working pressure and 
temperature, since the optimisation of the experimental conditions represent a critical step in the development of a SFE process. In this work, the extraction pressure and temperature were set to $30 \mathrm{MPa}$ and $313 \mathrm{~K}$ respectively, using pure $\mathrm{CO}_{2}$ since previous experiments using extraction pressures of 12,18 and $35 \mathrm{MPa}$ resulted in extracts with a lower quantity of essential oils than using $30 \mathrm{MPa}$ (data not shown). These results were also in agreement with previous studies done in our laboratory with rosemary, oregano and laurel leaves (García-Risco et al., 2011; Ocaña-Fuentes et al., 2010; Santoyo et al., 2006a; Santoyo et al., 2006b). As already mentioned, the extraction system employed in the present study allows a cascade of depressurization providing two different extracts: $\mathrm{S} 1$ and S2. The main difference between S1 and S2 extracts was the fractionation pressure, which brought about a gradual precipitation of the extracted compounds on the basis of their solubility in the extracting agent at the conditions set in each separator. These two extracts are expected to present different characteristics in terms of both, composition and functional activity. Therefore, in this work, the anti-inflammatory activity of S1 and S2 extracts of sage using an in vitro model of atherosclerosis was investigated.

\subsection{Effects of supercritical sage extracts on THP-1/M viability}

Sage supercritical extracts (S1 and S2) were initially evaluated for cytotoxicity on THP1/M cells by MTT method. The $\mathrm{CC}_{50}$ data obtained (Table 1) indicated that extract recovered in separator 2 presented a lower cytotoxicity than extract from separator 1 . However, at the higher concentration used in the (anti-inflammatory) assays, $30 \mu \mathrm{g} / \mathrm{mL}$, both extracts (S1 and S2) presented no cytotoxicity. Also S/L extracts at $30 \mu \mathrm{g} / \mathrm{mL}$, presented no cytotoxicity. 
259

The activation of THP-1/M was carried out with the addition of ox-LDLs to the medium. These ox-LDLs treated cells showed, after an incubation period of $24 \mathrm{~h}$, an important increase in the release of all pro- and anti-inflammatory cytokines tested (TNF- $\alpha$, IL-1 $\beta$, IL-6 and IL-10) compared to non-activated controls (Figure 1). These activated cells were considered as positive controls for all the cytokines tested. When the activation of THP-1/M was carried out in presence of sage extracts, a decrease in TNF- $\alpha$ secreted level was observed (Figure 1A), compared with levels obtained in absence of extracts (positive control). Moreover, a very significant decrease in the amount of TNF- $\alpha$ secreted was obtained with $30 \mu \mathrm{g} / \mathrm{mL}$ of extracts, where TNF- $\alpha$ secretion was even lower than basal level in non-activated cells. At this concentration, S1 extract produced a lower TNF- $\alpha$ secretion than S2 extract. Regarding to IL-1 $\beta$ secretion by activated cells in presence of sage extracts (Figure 1B), it can be also observed an important decrease in the secretion of this cytokine, with values close to basal levels presented by non-activated cells. However, in this case, the different concentrations of sage extracts employed presented a similar decrease in IL- $1 \beta$ release, indicating that the decrease was not related to the extract concentration. This data could be explained because the lowest concentration employed in this work $(10 \mu \mathrm{g} / \mathrm{mL})$ was already able to decrease the IL-1 $\beta$ release to basal levels. In this case, S1 extract induced a lower secretion of IL-1 $\beta$ than S2 extract too. The activation of macrophages in presence of supercritical extracts also produced a decrease in the IL-6 release (Figure 1C), although an extract concentration higher than $20 \mu \mathrm{g} / \mathrm{mL}$ was required. With this cytokine, S1 and S2 extracts presented a similar activity. Regarding IL-10, an antiinflammatory cytokine, the presence of extracts did not increase its release. 
282 These data indicated that supercritical sage extracts presented anti-inflammatory activity in THP-1 human macrophages activated with human ox-LDL, since these extracts effectively inhibited the release of pro-inflammatory cytokines as TNF- $\alpha$, Il-1 $\beta$ and IL6.

In order to compare the results obtained with supercritical extracts with $\mathrm{S} / \mathrm{L}$ extracts, 30 $\mu \mathrm{g} / \mathrm{mL}$ of these $\mathrm{S} / \mathrm{L}$ extracts were added to THP-1/M activated with ox-LDLs (data not included). Results shown that methanol:chloroform extract decreased the secretion of TNF- $\alpha$ and IL-6 compared to positive control, meanwhile IL-1 $\beta$ was not affected. However, ethanol extract only reduced the secretion of IL-6. When compared these results with those obtained with supercritical extracts, it can be concluded that S/L extracts presented a lower decrease of pro-inflammatory cytokines secretion.

\subsection{Effect of supercritical sage extracts on the cytokines mRNA expression}

In order to determine if the influence of the supercritical sage extracts in cytokine production was related to gene expression, total cellular RNA was extracted from activated THP-1/M and available for RT-PCR. The effect of sage extracts $(30 \mu \mathrm{g} / \mathrm{mL})$ on TNF- $\alpha$, IL-1 $\beta$, IL-6 and IL-10 mRNA expression in THP-1/M after $24 \mathrm{~h}$ of ox-LDLs activation is presented in Figure 2. TNF- $\alpha$ gene expression was significantly reduced by both S1 and S2 extracts, compared to the expression of activated cells in absence of the extracts. Similar results were obtained for IL-1 $\beta$ and IL-6, where extracts significantly decreased the expression of these interleukins. The decrease in TNF- $\alpha$, IL- $1 \beta$ and IL-6 gene expression was in agreement with cytokine release indicated before, which strengthen the anti-inflammatory activity of sage extracts. 
305 Regarding data obtained with IL-10, sage extracts significantly increase its mRNA expression, although, as shown previously, these extracts did not increase the release of

307 IL-10. This result could be explained due to IL-10 presented a slower response to oxLDL activation than other interleukins tested (Wasaporn et al., 2012).

\subsection{GC-MS characterization of supercritical sage extracts}

311 In an attempt to identify the compounds responsible for the anti-inflammatory activity

312 found in supercritical sage extracts, a characterization by GC-MS of these samples was

313 carried out. Results obtained are shown in Table 2, where a tentative identification has been performed based on the comparison of mass spectra and retention index (RI). As can be observed, 16 compounds were identified. Some of them were detected in large amounts like camphor, borneol and 1,8-cineole. The sum of these three compounds represented a $62.4 \%$ of the $\mathrm{S} 1$ extract; meanwhile extract obtained on separator 2 contained a smaller quantity $(48.1 \%)$ of these compounds. In order to correlate the antiinflammatory activity found in the supercritical extracts with their chemical composition, the cytotoxicity and anti-inflammatory activity of pure standards of these three main components of the extracts (camphor, borneol and 1,8-cineole) were also examined at the same conditions. The cytotoxicity assays revealed that these compounds were more cytotoxic than supercritical extracts, specially 1,8-cineole and borneol (Table 1). The concentrations used to carry out the experiments $(7.5$ and 5 $\mu \mathrm{g} / \mathrm{mL}$ ) presented $100 \%$ cell viability in all cases.

When the activation of THP-1/M was carried out in presence of camphor, borneol and 1,8-cineole, an important decrease in TNF- $\alpha$ secreted level was observed, especially when employing $7.5 \mu \mathrm{g} / \mathrm{mL}$ (Figure 1A). At this concentration, borneol and 1,8-cineole 
were more active than camphor, since they produced a lower TNF- $\alpha$ secretion. Figure

$3301 \mathrm{~B}$ also showed an important decrease in the secretion of IL-1 $\beta$, with values close to basal levels, with $7.5 \mu \mathrm{g} / \mathrm{mL}$ of camphor, 1,8-cineole and borneol. In this case, no differences were found among the three compounds. The IL-6 release (Figure 1C), also presented a great decrease in presence of camphor, 1,8-cineole and borneol. These data indicated that the three compounds presented an important anti-inflammatory activity. However, camphor, 1,8-cineole and borneol did not increase the release of the antiinflammatory cytokine IL-10 (Figure 1D) at the concentrations used.

Also, formulation of model mixtures with pure standards, mimicking the composition of the $\mathrm{S} 1$ and $\mathrm{S} 2$ extracts based on the compositions of Table 2, were carried out. When the activation of THP-1/M was studied in presence of these mixtures, at $30 \mu \mathrm{g} / \mathrm{mL}$, an important decrease in all cytokines studied was found (Figure 1). When these results were compared with those obtained with supercritical extracts, no significant differences were found.

The effect of camphor, 1,8-cineole and borneol $(7.5 \mu \mathrm{g} / \mathrm{mL})$ on TNF- $\alpha$, IL-1 $\beta$, IL-6 and IL-10 mRNA expression in THP-1/M after 24h of ox-LDLs activation was also studied (Figure 2). TNF- $\alpha$, IL-1 $\beta$ and IL-6 gene expression was significantly reduced by the three compounds tested. Regarding IL-10 gene transcription, an important increase was observed when activation was carried out in presence of camphor, borneol and 1,8cineole. Surprisingly, this important increase in IL-10 gene expression was not related with data obtained in the secretion of these IL-10 measured by ELISA. This result, found also for sage extracts, could be related with the time of the treatment, since a $24 \mathrm{~h}$ treatment could be able to increase the gene expression but not the release of this 
cytokine to medium, due to IL-10 presented a slower response to ox-LDL stimulation than other cytokines.

354 Thus, these compounds presented an important anti-inflammatory activity in the proposed model, with a decrease in the release and gene expression of pro-inflammatory cytokines and an increase in gene expression of IL-10, an anti-inflammatory cytokine. However, data did not show important differences among the activity of the three compounds. Accordingly borneol, camphor and 1,8-cineole could be proposed as the principal compounds responsible for the anti-inflammatory activity found in supercritical sage S1 and S2 extracts. Data also explained the higher activity found in extract obtained in S1, since this fraction contained a higher quantity of borneol, camphor and 1,8-cineole than extract S2). TNF- $\alpha$, IL-1 $\beta$ and IL-6 gene expression using model mixtures of pure standards did not presented significant differences compare with results obtained when using supercritical extracts (data not shown).

\section{Discussion}

Low-density lipoprotein oxidation appears to be a fundamental event in the development of the atherosclerotic lesion and the initiation of the inflammatory cascade (Call et al., 2004). Ox-LDL can induce the expression of pro-inflammatory cytokines, such as IL-1 $\beta$, TNF- $\alpha$ and IL-6 from monocytes and macrophages. IL-1 $\beta$ and TNF- $\alpha$ are

371 primary pro-inflammatory cytokines, which are mainly produced by monocytes and macrophages, and play a crucial role in the initial amplification of the inflammatory response. In vivo and in vitro research has highlighted their potential pro-atherogenic action. In particular, it has been shown that both IL-1 $\beta$ and TNF- $\alpha$ could induce the 
expression of adhesion molecules by endothelial cells, promote secretion of different cytokines and chemokines by monocytes, and may enhance the smooth muscle cells proliferation and migration (Rattazzi et al., 2004). They can also actively participate in the process of foam cell formation mainly through the induction of grown factors. These cytokines also play a crucial role in the later stage of atheroma development by hampering plaque stability (Young et al., 2002). IL-6 is a secondary inflammatory cytokine produced by different kinds of cellular elements such as activated macrophages, lymphocytes, fibroblast, and vascular smooth muscle cells under stimulation by IL-1 and TNF- $\alpha$. IL-6 may exert an important direct pathogenic role in atherosclerosis development and progression, especially through inflammatory elements recruitment and smooth muscle cells activation (Rattazzi et al., 2004).

The aim of this study was to investigate the anti-inflammatory capacity of supercritical Salvia officinalis extracts using THP-1 human macrophages activated with human oxLDL, since this model of inflammation allowed us to determine the anti-inflammatory effect of the extracts in an atherosclerotic environment and could be useful to determine the potential activity of the extracts in the prevention of atherosclerosis. The results suggested that supercritical sage S1 and S2 fractions may act as effective inhibitors of ox-LDL induced pro-inflammatory cytokines (TNF- $\alpha$, IL-1 $\beta$ and IL-6). Moreover, a very significant decrease in the secretion of these cytokines was obtained with 30 $\mu \mathrm{g} / \mathrm{mL}$ of sage extracts, since pro-inflammatory cytokines secretion levels with this concentration were even lower than its basal level in non activated cells. These results were also in agreement with the ones obtained regarding the transcription of cytokines genes at $24 \mathrm{~h}$ of incubation. In that way, Mueller et al. (2010), also reported that an extract from sage leaves was able to reduce the secretion of pro-inflammatory cytokines 
TNF- $\alpha$ and IL-6 in a lipopolysaccharide-stimulated macrophage model, although the

400

401

402

403

404

405

406

407

408

409

410

411

412

413

414

415

416

417

418

419

420

421

422

extract concentrations employed in this study were $0.2-0.5 \mathrm{mg} / \mathrm{mL}$. Other authors also reported the anti-inflammatory activity of sage extracts, although the anti-inflammatory activity was evaluated using the 5-lipoxigenase enzyme (Kamatou et al., 2010). The $\mathrm{IC}_{50}$ values reported for sage extracts against 5-lipoxygenase enzyme were greater than $100 \mu \mathrm{g} / \mathrm{mL}$, with the exception of Salvia radula $\left(\mathrm{IC}_{50}\right.$ value: $78.8 \mu \mathrm{g} / \mathrm{mL}$ ). Besides, a Salvia miltiorrhiza extract also suppressed LPS-induced TNF- $\alpha$ in human peripheral leukocytes and the Raw 264.7 macrophage cell line (Wang et al., 2006). Therefore, it is likely that small doses of supercritical sage extracts $(30 \mu \mathrm{g} / \mathrm{mL})$ inhibit ox-LDL induced TNF- $\alpha$, IL-1 $\beta$ and IL-6 production by THP-1 human macrophages preventing cytokine stimulation, which may contribute to the anti-inflammatory effect in atherosclerotic condition.

IL-10 is an anti-inflammatory cytokine that inhibits the production of IL- 2 and INF- $\gamma$ by Th1 cells, reduces pro-inflammatory cytokines production and down-regulated eosinophil function and activity (Konno et al., 2006). Results obtained in this work indicated that sage supercritical extracts significantly increase IL-10 mRNA expression by the activated macrophages, although these extracts did not produce a significant increased in IL-10 release at $24 \mathrm{~h}$ of stimulation. According to these data, Chen et al. (2011), reported that Salvianolic acid B, a compound isolated from dry root of Salvia miltiorrhiza enhanced the expresion of IL-10.

Main compounds presented in supercritical sage extracts were camphor, borneol and 1,8-cineole. These compounds represented a $62.4 \%$ in $\mathrm{S} 1$ extract and a $48.1 \%$ in $\mathrm{S} 2$ extract. These results indicated that the fractionation step increased the oxygenated monoterpenes composition in the extract obtained in the first separator. Similar results 
were reported by Fornari et al. (2012) using a similar procedure. Gañán and Brignole

424 (2013) also showed that a SFE fractionation of S. officinalis essential oil enriched sage extract in oxygenated monoterpenes, being 1,8-cineol, $\alpha$-thujone, $\beta$-thujone and camphor the main compounds.

A concentration of $7.5 \mu \mathrm{g} / \mathrm{mL}$ of 1,8-cineol, camphor and borneol showed an important decrease in both soluble levels and gene expression of TNF- $\alpha$, IL-1 $\beta$ and IL-6 by stimulated THP1/M. IL-10 gene expression at $24 \mathrm{~h}$ was also up-regulated by the presence of $7.5 \mu \mathrm{g} / \mathrm{mL}$ camphor, borneol and 1,8-cineole. The anti-inflammatory activity showed by these components was in agreement with the results showed by Juergens et al. (2004), who reported 1,8-cineole as a strong inhibitor of TNF- $\alpha$, IL-1 $\beta$ and IL-6 production by human unselected lymphocytes and LPS-stimulated monocytes. Santos and Rao (2000), also reported the inhibitory effect of 1,8-cineole, a terpenoid oxide present in many plant essential oils, on the pro-inflammatory cytokines production by stimulated monocytes. Regarding borneol, Tung et al. (2008), indicated that this compound exhibited excellent anti-inflammatory activity in suppressing nitric oxide production by LPS-stimulated macrophages. In addition, camphor has been also reported to have significant anti-inflammatory activity (Yoon et al., 2010; Chainy et al., 2000). The mixtures prepared with camphor, 1,8-cineol and borneol in order to simulate the composition of extract S1 and S2 have showed a similar anti-inflammatory effect than the supercritical extracts. These results were expected since these pure standards represented a $62.4 \%$ of the $\mathrm{S} 1$ extract and a $48.1 \%$ of S2 and these compounds, when using individually, have demonstrated a potent anti-inflammatory activity.

445 Concluding, supercritical fluid extraction allowed the production of sage extracts with an important anti-inflammatory activity using an atherosclerotic environment model. 
447 These extracts act as effective inhibitors of ox-LDL induced pro-inflammatory

448 cytokines (TNF- $\alpha$, IL-1 $\beta$ and IL-6) and therefore have a great potential to be used as 449 anti-inflammatory agents in the prevention of atherosclerosis.

\section{Acknowledgments}

451 Financial support from Spanish Ministry of Science and Innovation (CICYT) (Project: 452 IPT-300000-2010-034) Ingredientes Saludables Mediterráneos Innovadores, 453 INNSAMED) and Comunidad Autónoma de Madrid (ALIBIRD, project S-505/AGR454 0153). E.A. thanks Spanish Ministry of Education for a FPU grant. 
Abu-Darwish, M. S., Cabral, C., Ferreira, I. V., Gonçalves, M. J., Cavaleiro, C., Cruz, M. T., Al-bdour, T. H., Salgueiro, L., 2013. Essential oil of common sage (Salvia officinalis L.) from Jordan: assessment of safety in mammalian cells and its antifungal and anti-inflammatory potential. BioMed. Res. Int. 1-9.

Aleksovski, S.A., Sovová, H., 2007. Supercritical CO2 extraction of Salvia officinalis L. J. Supercrit. Fluid. 40, 239-245.

Alves, M. R., Sales, L. K., Machado das Nevesa, T., Francielle da Silva, C., Horstb, H., Geraldo M., Soares, A. R., Hatsuko, C., Werner, M., 2012. Antinociceptive and anti-inflammatory potential of extract and isolated compounds from the leaves of Salvia officinalis in mice. J. Ethnopharmacol. 139, 519- 526.

Barter, P., 2005. The inflammation: Lipoprotein cycle. Atherosclerosis. 6, 15-20.

Call J.T., Deliargyris E.N., Newby L.K., 2004. Focusing on inflammation in the treatment of atherosclerosis. Cardiol. Rev. 12, 194-200.

Çadirci, E., Süleyman, H. Gürbüz, P., Kuruüzüm uz, A., Güvenalp, Z., Demirezer, L. Ö., 2012. Anti-inflammatory effects of different extracts from three Salvia species. Turk J Biol. 36, 59-64.

Chainy, G.B., Manna, S.K., Chaturvedi, M.M., Aggarwal, B.B., 2000. Anethole blocks both early and late cellular responses transduced by tumor necrosis factor: effects on NF-kappa $\beta$, Ap-1, JNK, MAPKK and apoptosis. Oncogene. 19, 29432950.

Chan, H.H., Hwang, T.L., Su, C.R., Reddy, M.V.B., Wu, T.S., 2011. Antiinflammatory, anticholinesterase and antioxidative constituents from the roots and the leaves of Salvia nipponica Miq. var. formosana. Phytomedicine. 18, 148-150.

Chen, T., Liu, W., Chao, X., Zhang, L., Qu, Y., Huo, J., Fei, Z., 2011. Salvianolic acid $B$ attenuates brain damage and inflammation after traumatic brain injury in mice. Brain. Res. Bull. 84, 163-168.

Chouinard, J.A., Grenier, G., Khalil, A., Vermette, P., 2008. Oxidized-LDL induce morphological changes and increase stiffness of endothelial cells. Exp. Cell Res. 314, 3007-3016.

Díaz-Maroto, M.C., Pérez-Coello, M.S., Cabezudo, M.D., 2002. Supercritical carbon dioxide extraction of volatiles from spices. Comparison with simultaneous distillation-extraction. J. Chromatogr. 947, 23-29.

Ehrnhöfer-Ressler, M. M., Fricke, K., Pignitter, M. Walker, J. M., Walker, J.J., Rychlik, M., Somoza, V., 2013. Identification of 1,8-cineole, borneol, camphor, and 
thujone as anti-inflammatory compounds in a Salvia officinalis L. infusion using human gingival fibroblasts. J. Agric. Food Chem. 61, 3451-3459.

493

494

Fornari, T., Vicente, G., Vázquez, E., García-Risco, M. R., Reglero G., 2012. Isolation of essential oil from different plants and herbs by supercritical fluid extraction. J. Chromatogr. A. 1250, 34- 48.

Gañán, N., Brignole, E. A., 2013. Supercritical carbon dioxide fractionation of $T$. minuta and $S$. officinalis essential oils: Experiments and process analysis. J. Supercrit. Fluid. 78, 12-20.

García-Risco, M.R., Hernández, E.J., Vicente, G., Fornari, T., Señoráns, F.J., Reglero, G., 2011. Kinetic study of pilot-scale supercritical $\mathrm{CO}_{2}$ extraction of rosemary (Rosmarinus officinalis) leaves. J. Supercrit. Fluid. 55, 971-976.

Glisic, S. B., Ristic, M., Skala, D. U., 2011. The combined extraction of sage (Salvia officinalis L.): Ultrasound followed by supercritical $\mathrm{CO}_{2}$ extraction. Ultrason Sonochem. 18, 318-326.

Havel, R.J., Eder, H.A., Bragdon, J.H., 1995. The distribution and chemical composition of ultracentrifugally separated lipoprotein in human serum. J. Clin. Invest. 34, 1345-1353.

Hamdy, M. H., Atef M., Abdel-Hamed, K., Ibrahim K., 2013. Evaluation of antioxidant activity, total phenols and phenolic compounds in thyme (Thymus vulgaris L.), sage (Salvia officinalis L.), and marjoram (Origanum majorana L.) extracts. Ind. Crop. Prod. 43, 827-831.

Juergens, U.R., Engelen, T., Racké, K., Stöber, M., Gillissen, A., Vetter, H., 2004. Inhibitory activity of 1,8-cineol (eucalyptol) on cytokine production in cultured human lymphocytes and monocytes. Pulm. Pharmacol. Ther. 17, 281-287.

Kaefer, C.M., Milner, J.A., 2008. The role of herbs and spices in cancer prevention. J. Nutr. Biochem. 19, 347-361.

Kamatou, G.P.P., Viljoen, A.M., Gono-Bwalya, A.B., Van Zyl, R.L., Van Vuuren, S.F., Lourens A.C.U., Baser, K.H.C., Demirci, B., Lindsey, K.L., Van Staden, J., Steenkamp, P., 2005. The in vitro pharmacological activities and a chemical investigation of three South African Salvia species. J. Ethnopharmacol. 102, 382390.

Kamatou, G.P.P., Makunga, N.P., Ramogola, W.P.N., Viljoen, A.M. 2008., South African Salvia species: A review of biological activities and phytochemistry. J. Ethnopharmacol. 119, 664-672. 
Kamatou, G.P.P., Viljoen, A., Steenkamp, P., 2010. Antioxidant, anti-inflammatory activities and HPLC analysis of South African Salvia species. Food Chem. 119, 684-688.

Kaperonis, E.A., Liapis, C.D., Kakisis, J.D., Dimitroulis, D., Papavassiliou, V.G., 2006. Inflammation and atherosclerosis. Eur. J. Vasc. Endovasc. 31, 386-393.

Konno, S., Eckman, J.A., Plunkett, B., Li, X., Berman, J.S., Schoroeder, J, Huang, S.K., 2006. Interleukin 10 and Th-2 cytokines differentially regulate osteopontin expression in human monocytes and dendritic cells. J. Interfer. Cytok. Res. 26, 562567.

Maksimovic, S., Kesica, Z., Lukica, I., Milovanovica, S., Risticb, M., Skalaa, D., 2013. Supercritical fluid extraction of curry flowers, sage leaves, and their mixture. J. Supercrit. Fluid. 84, 1-12.

Mosmann T., 1983. Rapid colorimetric assay for cellular growth and survival: application to proliferation and cytotoxicity assays. J. Immunol. Methods. 65, 55-63.

Mueller, M., Hobiger, S., Jungbauer, A., 2010. Anti-inflammatory activity of extracts from fruits, herbs and spices. Food Chem. 122, 987-996.

Ocaña-Fuentes, A., Arranz-Gutierrez, E., Señorans, F.J., Reglero, G., 2010. Supercritical fluid extraction of oregano (Origanum vulgare) essential oils: Antiinflammatory properties based on cytokine response on THP-1 macrophages. Food Chem. Toxicol. 48, 1568-1575.

Rattazzi, M., Shoenfeld, Y., Pauletto, P., 2004. Innate Immunity, Inflammation, and Atherogenesis, in: Doria, A., Pauletto, P. (Eds.), Hadbook of Systemic Autoimmune Diseases. Elsevier, New York, pp. 77-88.

Santos, F.A., Rao, V.S.N. 2000. Antiinflammatory and antinociceptive effects of 1,8-cineole a terpenoid oxide present in many plant essential oils. Phytother. Res. 14, 240-244.

Santoyo, S., Cavero, S., Jaime, L., Ibáñez, E., Señorans, F.J., Reglero, G., 2006a. Supercritical carbon dioxide extraction of compounds with antimicrobial activity from Origanum vulgare L. Determination of optimal extraction parameters. J. Food Protect. 69, 369-375.

Santoyo, S., Lloria, R., Jaime, L., Ibañez, E., Señorans, F.J., Reglero, G., 2006b. Supercritical fluid extraction of antioxidant and antimicrobial compounds from Laurus nobilis L. Chemical and functional characterization. Eur. Food Res. Technol. 222, 565-571.

Shin, T.Y., Kim, H.M., 2002. Inhibition of immediate-type allergic reactions by the aqueous extract of Salvia plebeia. Immunophar. Immunot. 24, 303-314. 
Tajkarimi, M.M., Ibrahim, S.A., Cliver, D.O., 2010. Antimicrobial herb and spice compounds in food. Food Control. 21, 1199-1218.

563 Tung, Y.T., Chua, M.T., Wang, S.Y., Chang, S.T., 2008. Anti-inflammation

564 activities of essential oil and its constituents from indigenous cinnamon (Cinnamomum osmophloeum) twigs. Bioresource Technol. 99, 3908-3913.

Wang, J.M., Sit, W.H., Lee, C.L., Fu, K.H., Chan, D.K., 2006. Protection of lethal toxicity of endotoxin by Salvia miltiorrhiza Bunge is via reduction in tumor necrosis factor alpha release and liver injury. Int. Immunopharm. 6, 750-758.

Wasaporn, C., Reitsma, M., Kleinjans, L., Mes, J.J., Savelkoul, H.F.J., Wichers, H.J., 2012. $\beta$-glucans are involved in immune-modulation of THP-1 macrophages. Mol. Nut. Food Res. 56, 822-833.

Yoon, W.J., Moon, J.Y., Song, G., Lee, Y.K., Han, M.S., Lee, J.S., Ihm, B.S., Lee, W.J., Lee, N.H., Hyun, C.G., 2010. Artemisa fukudo essencial oil attenuates LPSinduced inflammation by suppressing NF- $\mathrm{BB}$ and MAPK activation in RAW 264.7 macrophages. Food Chem. Toxicol. 48, 1222-1229. atherosclerosis. Thromb. Haemostasis. 88, 554-558. 
579 Table 1. THP-1/M cell viability in presence of supercritical sage extracts and pure 580 standards. $\mathrm{CC}_{50}$ (cytotoxic concentration 50\%): concentration required to reduce $50 \%$ 581 the number of viable THP-1/M cells after $24 \mathrm{~h}$ of incubation with the compounds. a,b,c,d 582 Different superscript letters indicated significant differences $(p<0.05)$ among data.

\begin{tabular}{ll} 
Sample & CC50 $(\boldsymbol{\mu g} / \mathbf{m L})$ \\
\hline Sage S1 & $66.70 \pm 5.41^{\mathrm{a}}$ \\
Sage S2 & $80.24 \pm 7.58^{\mathrm{b}}$ \\
Camphor & $55.75 \pm 6.12^{\mathrm{c}}$ \\
1,8-Cineole & $35.32 \pm 4.21^{\mathrm{d}}$ \\
Borneol & $26.93 \pm 2.78^{\mathrm{d}}$
\end{tabular}

583

584

585

586

587

588

589

590

591

592

593

594

595

596

597 
598 Table 2. GC-MS identification, peak area contribution (normalized area percent), and 599 retention index (RI) of compounds found in supercritical extracts (S1 and S2) from sage 600 (Salvia officinalis). NI: non-identified compound, n.d.: non detected.

601

\begin{tabular}{|c|c|c|c|c|}
\hline $\begin{array}{l}\text { Retention time } \\
\qquad(\mathrm{min})\end{array}$ & $\mathbf{R I}$ & Compound & $\begin{array}{c}\text { S1 } \\
\text { normalized } \\
\text { area }(\%)\end{array}$ & $\begin{array}{c}\text { S2 } \\
\text { normalized } \\
\text { area }(\%)\end{array}$ \\
\hline 13.33 & 1029 & 1,8-Cineole & 13.34 & 4.64 \\
\hline 17.38 & 1099 & Linalool & 1.16 & 1.10 \\
\hline 19.64 & 1138 & Cis-sabinol & 2.05 & n.d. \\
\hline 19.78 & 1140 & Camphor & 41.78 & 33.9 \\
\hline 21.07 & 1163 & Borneol & 7.28 & 9.56 \\
\hline 22.55 & 1188 & Alpha-terpineol & 1.16 & 1.81 \\
\hline 26.44 & 1253 & Linalyl acetate & 4.86 & 5.81 \\
\hline 28.19 & 1282 & Endobornyl acetate & 3.19 & 3.46 \\
\hline 28.70 & 1291 & Sabinyl acetate & 5.00 & 5.94 \\
\hline 32.60 & 1345 & $\alpha$-terpinenyl & 3.68 & 4.71 \\
\hline 37.84 & 1412 & E-cariophyllene & 2.33 & 2.97 \\
\hline 40.65 & 1484 & $\alpha$-humulene & 1.75 & 2.41 \\
\hline 43.05 & 1535 & Geranyl propionate & 1.25 & 1.91 \\
\hline 51.19 & 1575 & Spathulenol & 1.01 & 2.05 \\
\hline 51.48 & 1579 & Cariophyllene oxide & 1.03 & 1.61 \\
\hline 52.04 & 1586 & viridiflorol & 2.00 & 4.02 \\
\hline 56.61 & 1685 & $\mathrm{NI}$ & 2.11 & 5.06 \\
\hline
\end{tabular}

602

603

604

605 
607 Figure 1: Levels of TNF- $\alpha$ (1A), IL-1 $\beta$ (1B), IL-6 (1C) and IL-10 (1D) secreted by 608 THP-1/M activated with ox-LDL in presence of supercritical sage extracts, pure 609 standards or mixtures of pure standards simulate sage S1 and S2 extracts. Each bar is 610 the mean of three determinations \pm standard deviation. ${ }^{*}$ Denotes statistical differences 611 between control+ox-LDL and the other samples at $p<0.05$. ${ }^{\mathrm{a}, \mathrm{b}}$ Columns with different 612 superscript letters are significantly different at $p<0.05$ (comparison between S1 and S2 sage extracts and mixtures of pure standards at $30 \mu \mathrm{g} / \mathrm{mL}$ ).

614

615 Figure 2: mRNA expression of TNF- $\alpha$ (2A), IL-1 $\beta$ (2B), IL-6 (2C) and IL-10 (2D) on 616 THP-1/M stimulated with ox-LDL in presence of supercritical sage extracts or pure 617 standards. Each bar is the mean of three determinations \pm standard deviation. RQ: 618 relative quantification. * Denotes statistical differences between control+ox-LDL and 619 the other samples at $p<0.05$.

620

621

622

623

624

625 

Figure 1

628

629

630

631

632

633

634

635

636

637

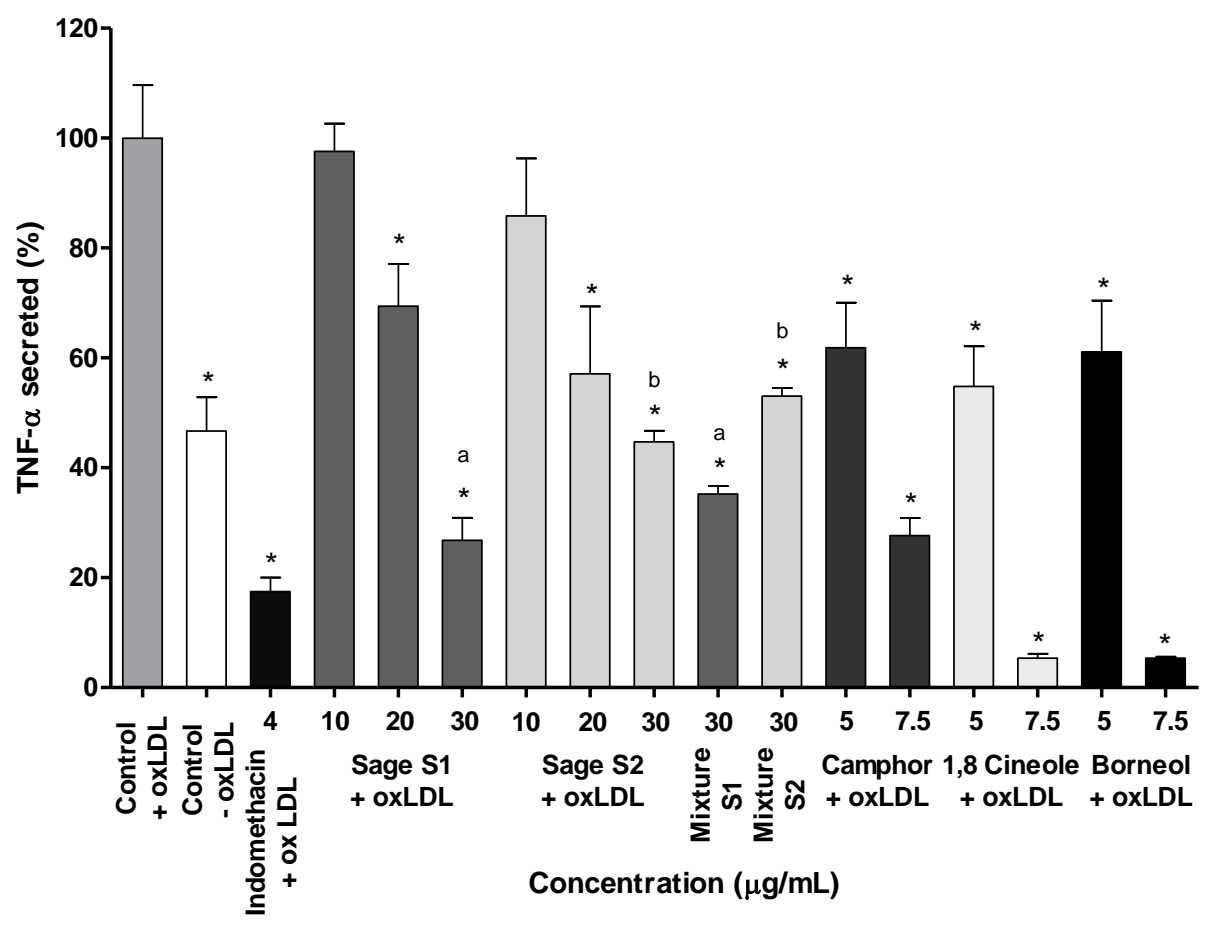

638

(A)

640

641

642

643

644

645

646

647

648

649

650

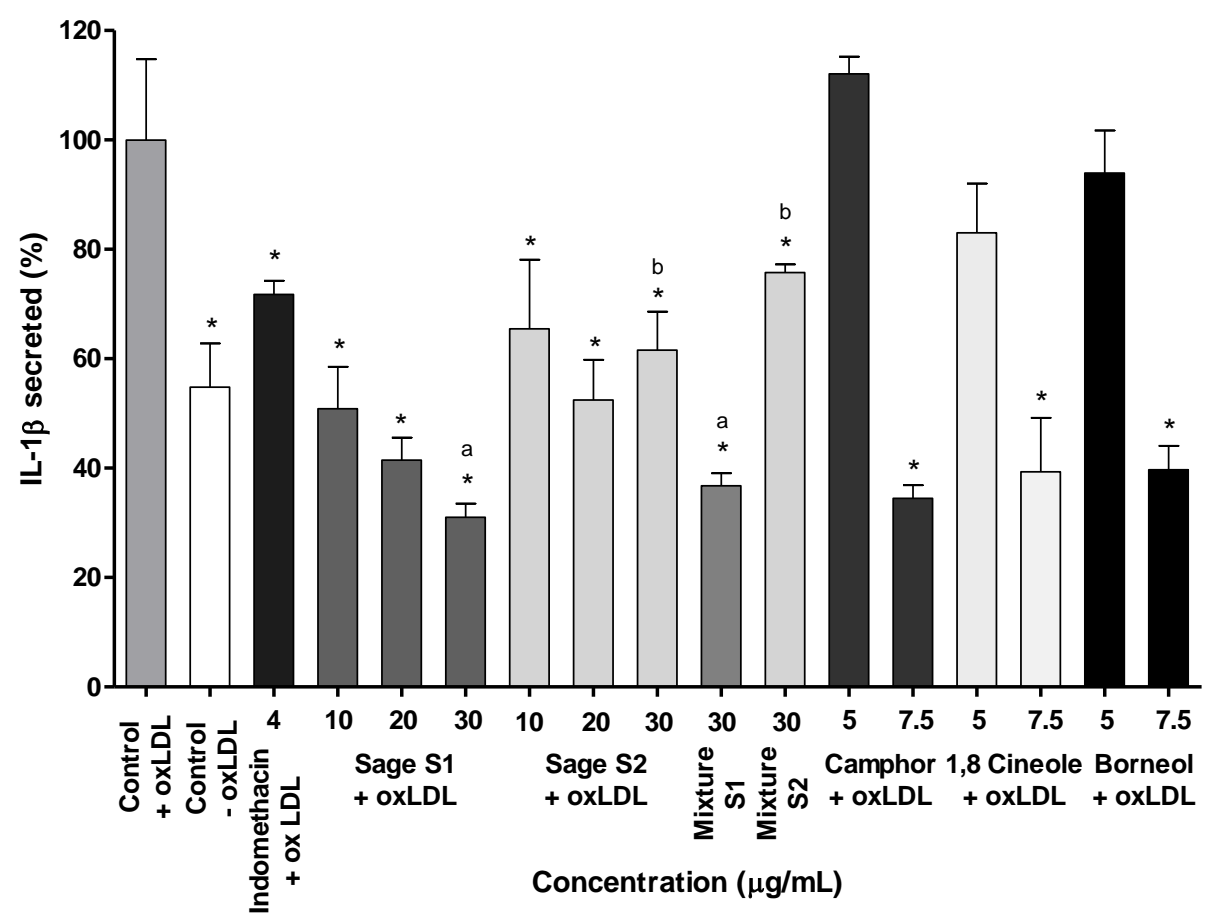

651

652

(B) 

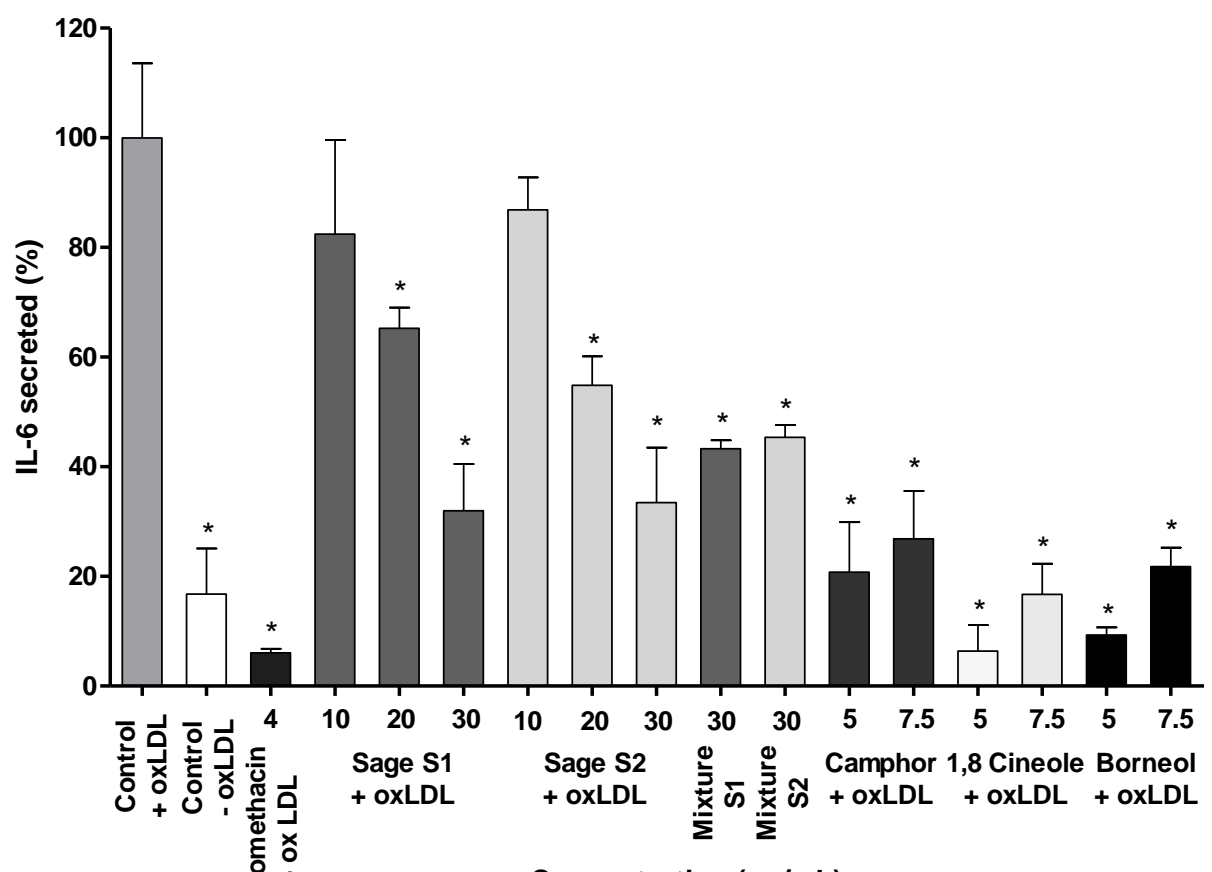

664

(C)

665

666

667

668

669

670

671

672

673

674

675

676

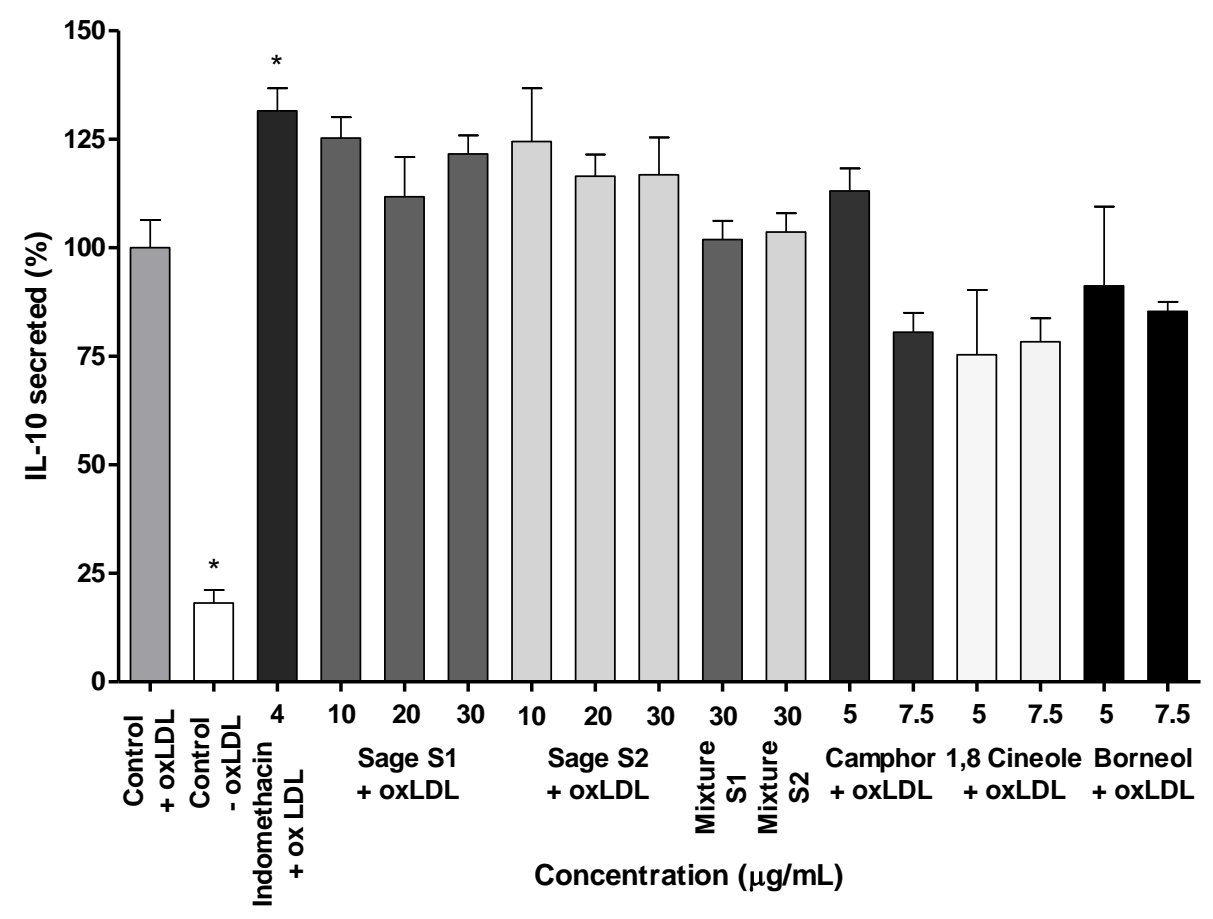

677

678

(D) 
680 Figure 2

681

682

683

684

685

686

687

688

689

690

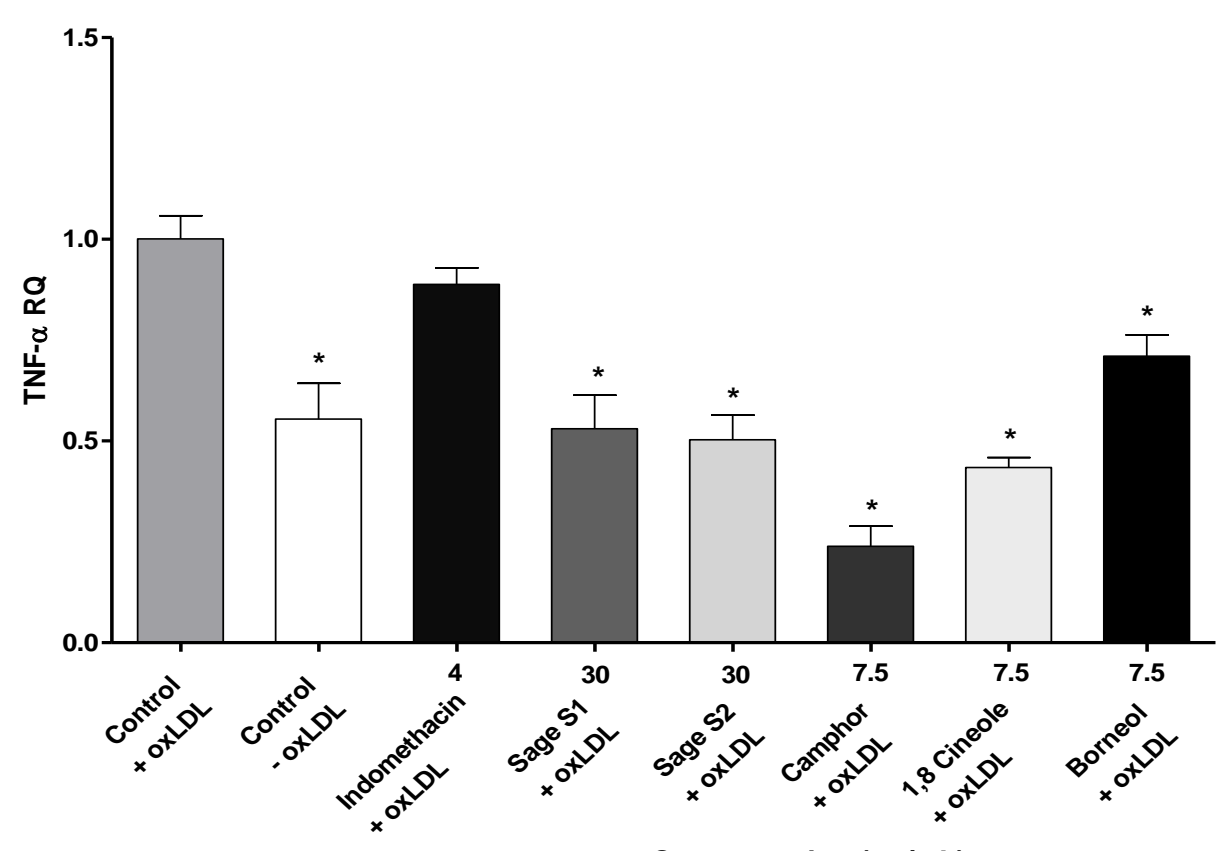

691

692

(A)

693

694

695

696

697

698

699

700

701

702

703

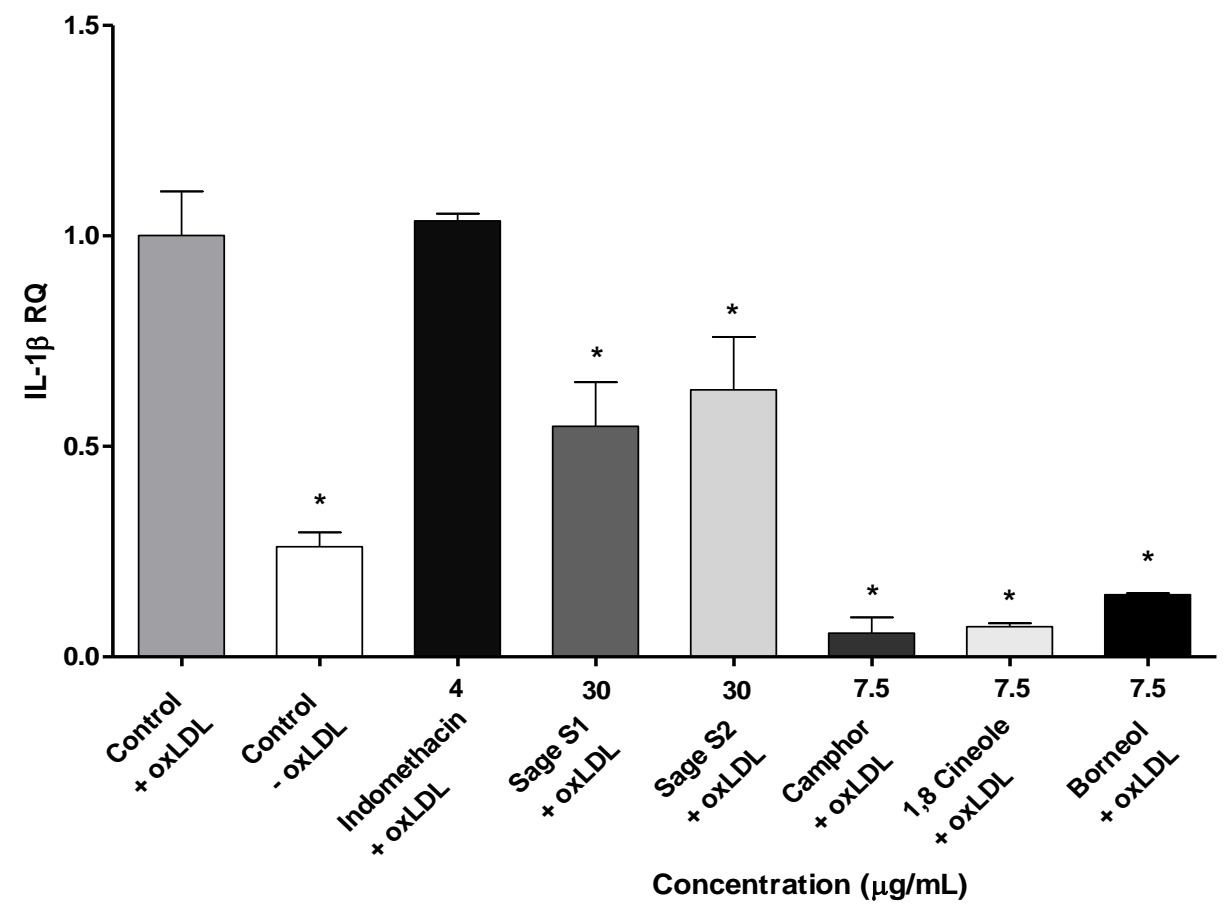

704

(B) 


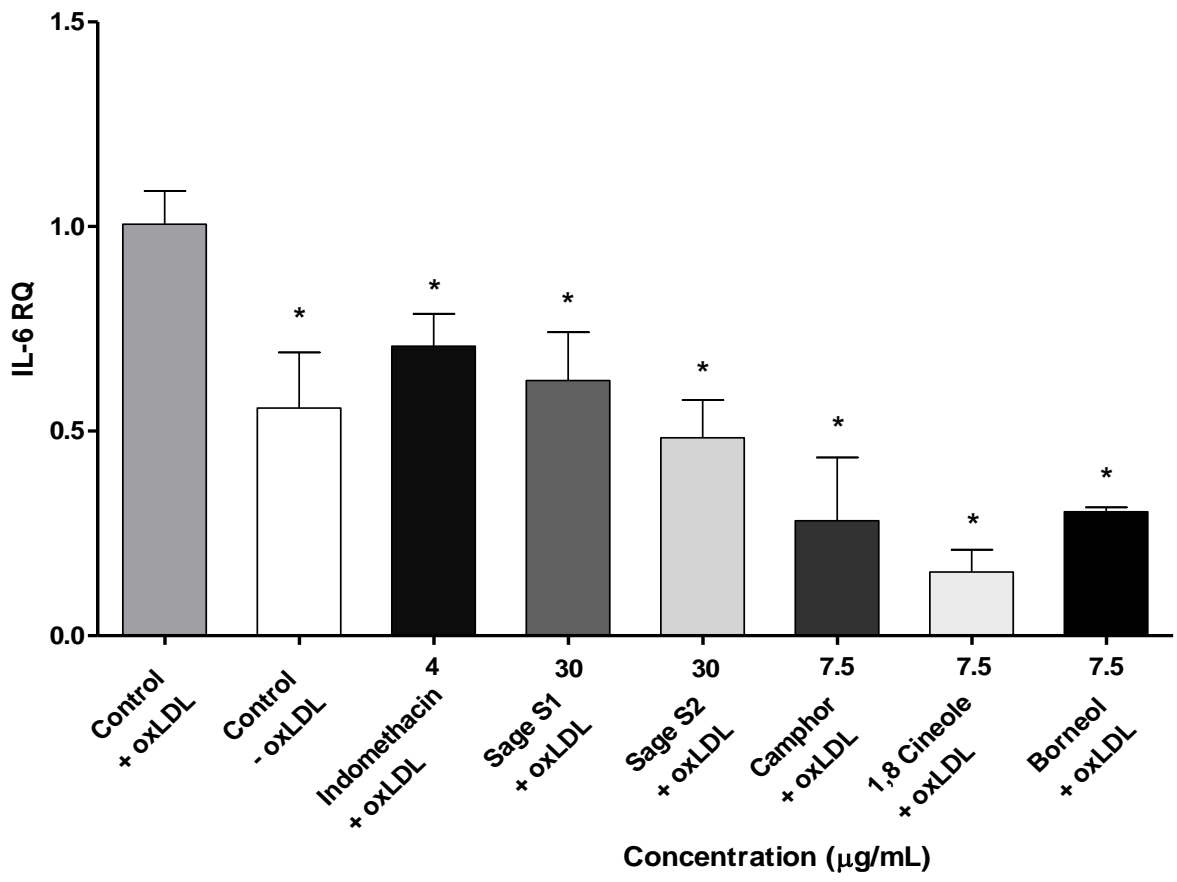

717

(C)

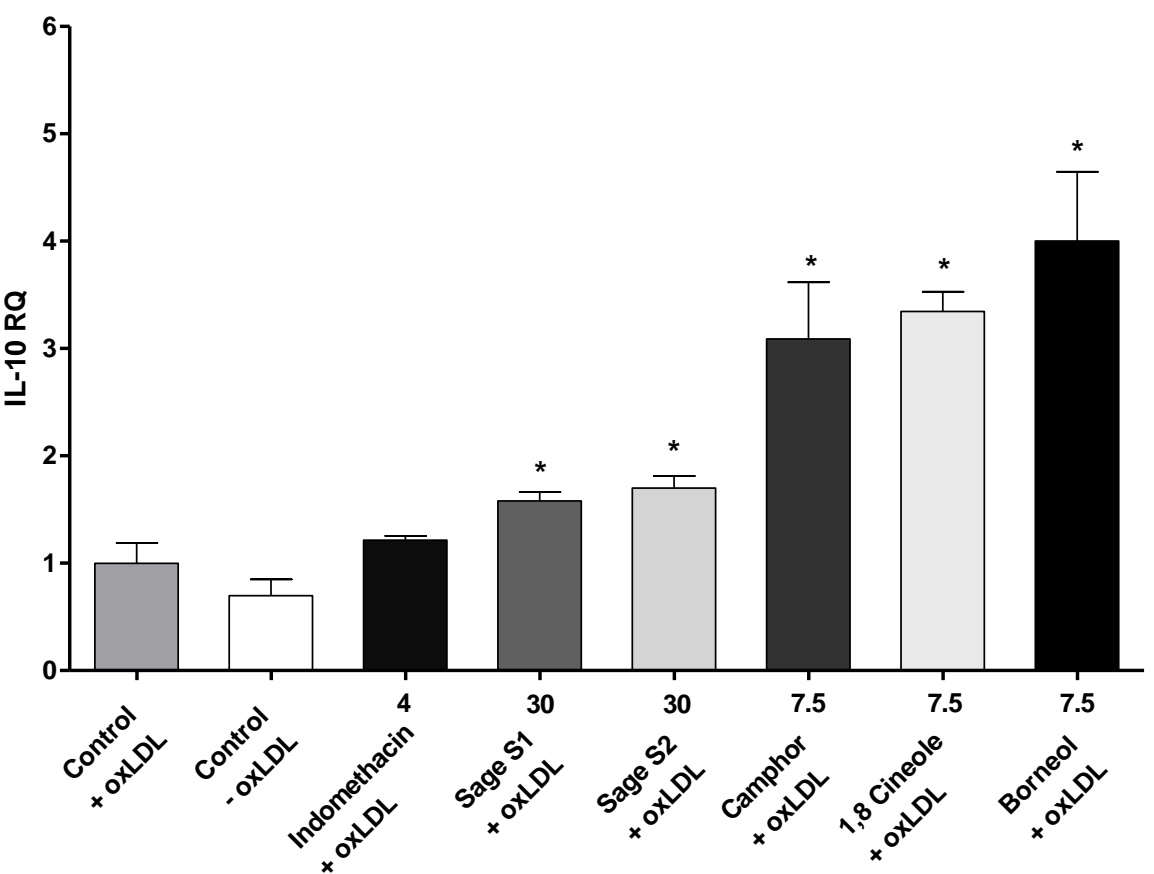

730

Concentration $(\mu \mathrm{g} / \mathrm{mL})$ 